\title{
La metodología de la concienciación feminista en la época de las redes sociales
}

The methodology of feminist consciousness-raising in the age of social networks

Dra. Tasia Aránguez Sánchez, Universidad de Granada, España Facultad de Derecho, Plaza de la Universidad, 1 (18001)

tasia@urg.es | Orcid: autorhttp://orcid.org/0000-0002-2691-0622

\section{DOI: http://dx.doi.org/10.12795/Ambitos.2019.i45.14}

\begin{abstract}
Resumen
La concienciación es una metodología feminista cuyo nombre se originó en los grupos de mujeres que se formaron en Estados Unidos en la década de los setenta (segunda ola feminista). En ellos cada mujer presentaba su vida. Algunos se movían por temas, como la maternidad, la imagen física o las relaciones sexuales, otros leían libros y compartían bibliografía, y otros ayudaban a las mujeres en momentos difíciles. El resultado de esas conversaciones es la formación de la conciencia de "clase sexual" que constituye el germen de la acción colectiva.

De los grupos de concienciación de los setenta emergieron conceptos fundamentales del feminismo como "patriarcado" o "clase sexual". Si el feminismo de los años setenta fue revolucionario, el feminismo de nuestros días, por medio de las redes sociales podría
\end{abstract}


alcanzar una escala sin precedentes. Este artículo se propone indagar en las similitudes entre el feminismo de la segunda ola y el de la cuarta ola (actual). El objetivo es dilucidar si las redes sociales posibilitan el desarrollo del citado método de la "concienciación", dando lugar a nuevos conceptos explicativos de la realidad política de las mujeres.

\section{Abstract}

Consciousness-raising is a feminist methodology whose name originated in the groups of women who were trained in the United States in the seventies (second wave feminism). In them, each woman presented her life. Some were organized by themes, such as motherhood, physical image or sexual relations, others read books and shared bibliography, and others helped women in difficult times. The result of these conversations is the formation of the "sexual class" consciousness that constitutes the seed of collective action.

From the consciousness-raising groups of the seventies emerged fundamental concepts of feminism as "patriarchy" or "sexual class". If the feminism of the seventies was revolutionary, the feminism of our days, through social networks, could reach an unprecedented scale. This article intends to investigate the similarities between the feminism of the second wave and that of the fourth wave (current). The objective is to elucidate whether social networks allow the development of the aforementioned method of consciousness-raising, originating new explanatory concepts of the political reality of women.

Palabras clave: redes sociales, feminismo, metodología, epistemología, concienciación

Keywords: social networks, feminism, methodology, epistemology, consciousness-raising

\section{INTRODUCCIÓN}

La metodología empleada en este trabajo es de tipo hermenéutico (Gadamer, 2013, p. 348). Partimos de la lectura de bibliografía que explica la epistemología feminista tal y como se articulaba en la década de los setenta. Estas lecturas son contrastadas con nuestra experiencia como activistas feministas en el tiempo de la redes sociales e indagamos si el contexto descrito por estos textos clásicos es análogo al contexto de nuestro tiempo, posibilitando una fusión entre ambos horizontes epistemológicos que nos permita comprender nuestra época a la luz de las semejanzas y diferencias con el pasado. 
En los años setenta en los Estados Unidos surgió la segunda ola del feminismo, cuya característica central desde el punto de vista epistemológico fue la concienciación, un método propio. En palabras de Catharine Mackinnon: "El método feminista es la creación de conciencia: la reconstrucción crítica y colectiva del significado de la experiencia social de la mujer, tal y como la viven las mujeres" (MacKinnon, 1995, p. 155) Una forma de analizar el feminismo de la segunda ola (también llamado "feminismo radical" por su intención de llegar hasta las causas-raíz de la opresión patriarcal) es describir el proceso de concienciación tal y como se produjo en los grupos de toma de conciencia de aquel momento histórico. MacKinnon explica que los grupos de concienciación solían ser el primer contacto explícito de las mujeres con el feminismo. Surgían espontáneamente entre amigas, en universidades, centros de mujeres, barrios, iglesias y lugares de trabajo, y por tanto tenían bases populares. Muchos tenían diversidad de edad, educación, capacidad física, sexualidad, raza, clase u opiniones políticas. Otros elegían la uniformidad en estos mismos aspectos. Algunos grupos giraban en torno a la biografía: cada mujer contaba su vida. Otros se movían por temas de debate como el lesbianismo, la maternidad, la imagen física o las relaciones sexuales. Algunos eran círculos de lectoras en los que se leían libros o se compartía bibliografía. Otros grupos ayudaban a las mujeres en momentos difíciles (superación del duelo, colaboración para la crianza o redes de ayuda para víctimas de violencia machista).

Un ejemplo de estos grupos fue el colectivo de mujeres de Boston, que empezó como un pequeño grupo de discusión sobre las mujeres y sus cuerpos, y surgió a raíz de una conferencia realizada en Boston en la primavera de 1969. Era el principio del feminismo de la segunda ola, uno de los primeros encuentros de mujeres reunidas específicamente para hablar con mujeres (Colectivo de Mujeres de Boston, 1979, p. 13). A partir de esa conferencia algunas mujeres decidieron formar un pequeño grupo para continuar con el debate. Al principio llamaban al grupo "el grupo médico", porque todas las mujeres que lo integraban habían pasado por experiencias de machismo en la atención sanitaria. Las conversaciones versaban sobre asuntos de salud y en ese camino de compartir experiencias aprendieron mucho sobre sus propios cuerpos. Gracias a la acción divulgativa del grupo fueron surgiendo muchos pequeños grupos que se interrogaban sobre la salud de las mujeres: un grupo se centraba en la menopausia, otro en la sexualidad humana, otro en los problemas específicos de las lesbianas con el sistema médico, etc.

El colectivo era a fin de cuentas un grupo de amigas que se reunían para resolver los problemas que tenían con hospitales o médicos y también para aprender sobre salud y compartir experiencias. El grupo permitía identificar los aspectos deficientes del sistema sanitario, reportando una información a la que es difícil acceder porque las pacientes del 
sistema sanitario suelen estar incomunicadas entre sí (por ejemplo, información sobre los tratamientos eficaces). La labor de estas mujeres fue muy importante para desvelar el androcentrismo médico y los defectos de las políticas públicas de atención sanitaria a las mujeres. Las asistentes experimentaron este movimiento como una experiencia política porque su existencia desafiaba al sistema sanitario. Eran grupos de mujeres relacionándose consigo mismas para transformar la atención sanitaria, aprender sobre sus cuerpos y tomar decisiones médicas informadas, gracias a su interés por la salud, cuyos conocimientos se enriquecían escuchando la experiencia de otras mujeres. Además de este colectivo, han existido desde entonces muchas experiencias de grupos médicos y movimientos asociativos basados en la ayuda mutua entre pacientes (reuniones de enfermas de cáncer de mama, grupos de preparación al parto, de experiencias de aborto o de lactancia natural).

Aunque, como expone Jo Freeman (1988, p.12) muchas veces los grupos de conciencia desarrollaban liderazgos espontáneos, estos grupos pretendían fundarse en una organización no jerarquizada y marcadamente horizontal. El primer impulso para acudir solía ser un descontento vital inespecífico que las mujeres relacionaban con el hecho de ser mujeres. MacKinnon expone el contenido de las conversaciones:

Se habla de la vida de las mujeres en toda su decisiva trivialidad, es decir, como se vive. La técnica explora el mundo social que cada mujer habita (...) a través de la comparación con la experiencia de otras mujeres. (...) Las metáforas de oír y hablar con frecuencia expresan la transformación que experimentan las mujeres desde el silencio hasta la voz. (MacKinnon, 1995, p. 160).

Cada mujer encuentra algo de su propia historia en el interior de las historias de otras mujeres. Aunque los detalles sean distintos y existan diferencias entre las mujeres, hay un significado común en los testimonios y precisamente ese significado común solo es comprensible a través de su concreción en los detalles diferenciales.

La concienciación permite comprender que lo personal es político, es decir, que los problemas que se creían personales son en realidad colectivos y que por tanto requieren soluciones colectivas. A partir de la narración de lo más cercano y lo más propio se accede a la comprensión sobre las estructuras sociales. Lejos de constituir un trivial intercambio de anécdotas, la concienciación supuso un caldo de cultivo perfecto para la proliferación de nuevos conceptos y categorías de análisis político. El intercambio de experiencias puso de manifiesto que el sexismo está omnipresente en la vida de las mujeres hasta el punto de que es preciso un enorme esfuerzo de concentración colectiva para poder verlo. La concienciación es ese esfuerzo. 
En nuestros días, como señala Ana de Miguel (2015, p. 207), internet ofrece al movimiento feminista la posibilidad de organizarse en redes sociales para denunciar los hechos que suceden bajo la indiferencia de los medios de comunicación convencionales. Internet constituye un espacio privilegiado para la participación gracias a los escasos recursos materiales que requiere el contacto. La red favorece la autonomía y la comunidad horizontal de las mujeres, continúa la autora, y se está desarrollando una esfera pública global, con una reubicación de lo político entre lo local, lo nacional y lo internacional. Coincidimos con las apreciaciones de Ana de Miguel pues la organización en redes sociales resulta idónea para la participación activa de mujeres que son madres, o que viven agotadas por la doble jornada y experimentan que no pueden cumplir satisfactoriamente todos los papeles sociales que les son impuestos. Tomar un rol activo en el movimiento feminista no requiere demasiado tiempo libre, pues ya no es imprescindible desplazarse ni asistir a reuniones. Se pueden intercambiar experiencias en grupos de redes sociales o de chat telefónico, y es posible divulgar, a través de estos grupos, vídeos y artículos de blogs, extendiendo exponencialmente estos nuevos grupos de conciencia. Eventualmente, la organización virtual en red, puede convocar a la movilización en las calles, obteniendo un éxito rotundo en el caso del feminismo español de la cuarta ola. El movimiento feminista que se articula en las redes sociales, al igual que los grupos de conciencia de la segunda ola, descansa sobre la autonomía de las mujeres, pues es un movimiento horizontal y difícil de conciliar con liderazgos y estructuras rígidas. El hecho de que los nuevos "grupos de conciencia" sean más accesibles en la era de internet facilita a las mujeres, que pasan más tiempo en el domicilio, formar parte de la organización colectiva. McCarthy y Zald (1977, p.1232) destacan la importancia de la organización colectiva como catalizadora de la movilización dado que disminuye el desgaste que implicaría una lucha solitaria: facilita las realización de acciones, contribuye a reclutar participantes, asigna tareas, almacena información y proporciona contactos y recursos. Es decir, unirnos al movimiento feminista no solo nos ayuda a redefinir la realidad, sino que también aumenta las posibilidades de transformar esa realidad con un nivel de trabajo asumible.

Un ejemplo de estos nuevos grupos virtuales de conciencia es el del colectivo de afectadas de endometriosis, una enfermedad crónica y dolorosa que tiene una de cada diez mujeres y que consiste en que el tejido endometrial prolifera fuera del útero, creando quistes y adherencias que "pegan" entre sí los órganos de la cavidad pélvica. A pesar de su alta prevalencia, esta enfermedad exclusiva de mujeres recibe escasa atención social, hasta el punto de que sus afectadas viven la enfermedad en un estado de confusión, soledad y en un contexto de desconfianza hacia su palabra de parte de profesionales de la salud, entorno laboral y familiar. En las redes sociales, en todos los continentes y en numerosos idiomas, el colectivo de afectadas ha conformado multitud de grupos en los 
que se comparten experiencias que sirven para intercambiar información y para tomar conciencia de que la invisibilidad de esta condición no tiene nada de anecdótico, sino que está relacionada con toda una historia de normalización y minimización del dolor femenino (máxime teniendo en cuenta que uno de sus síntomas más característicos es el intenso dolor menstrual). Esa toma de conciencia es el paso previo para una labor de activismo que se incardina dentro del movimiento feminista, en la línea de los mencionados grupos que luchaban por hacer efectivo el derecho de las mujeres a la salud.

\section{EL MÉTODO DE LA CONCIENCIACIÓN FEMINISTA}

El método de la concienciación se resume en el lema "lo personal es político". MacKinnon (1995, p. 165) expone los cuatro descubrimientos epistémicos que caracterizan al método: El primero consiste en reparar en que las mujeres como grupo están dominadas por los hombres como grupo. El segundo consiste en darse cuenta de que la subordinación no tiene causa en las elecciones personales de cada mujer ni en la naturaleza de las mujeres. El tercero consiste en reparar en que existe una división sexual del trabajo que condena a las mujeres a la subordinación y que determina incluso los sentimientos personales en las relaciones de amor y amistad que entablan las mujeres. El cuarto es que "puesto que los problemas de una mujer no son suyos individualmente, sino que son los de las mujeres en su conjunto, no pueden resolverse si no es como conjunto". La concienciación permite que las mujeres se quiten la culpa y que expliquen sus propios sentimientos como respuestas racionales a su situación y no como consecuencia de que estén locas, sean inadaptadas, tengan problemas hormonales, sean malas 0 desagradecidas. Muchas se dan cuenta de que han sido privadas de capacidad, pero no son incapaces. Esto no implica que las mujeres den validez a la sociedad que les obliga a sentir eso. La concienciación no tiene la finalidad de dar brillo a las cadenas ni de hacer más llevadera la opresión pensando que el mal se comparte con muchas. El objetivo es, en todo momento, orientar esos sentimientos de insatisfacción hacia la transformación social mediante la acción colectiva.

La concienciación es el proceso en el que las mujeres toman conciencia de su opresión como algo común y estructural en tanto que mujeres, en lugar de quedarse con unos malos sentimientos de causa desconocida. El momento fundamental de la concienciación es cuando las mujeres descubren que existe una realidad vital compartida suficiente para proporcionar la base para la identificación, para comenzar el diálogo en un grupo de mujeres. La conciencia de "clase sexual" que surge, es la precondición de la organización feminista y de su acción colectiva. 
Cuando las mujeres exponían sus vidas en los grupos de conciencia de los años setenta, se ponía el foco sobre las estructuras patriarcales que vertebran las vidas. Un descubrimiento adquirido mediante la concienciación fue que, contrariamente a lo que les habían prometido desde la infancia, la mayoría de mujeres sentía que ni el matrimonio, ni la maternidad, ni la feminidad les satisfacían por completo. Todas experimentaban frustración por el hecho de que ser esposas y madres había supuesto una merma considerable a sus carreras laborales y necesitaban tiempo para su trabajo o para sí mismas. Meredith Tax expone el testimonio de una de aquellas mujeres:

Solo existo porque me necesita alguien que es real, mi marido y también mis hijos. $\mathrm{Mi}$ marido sale al mundo real. (...) Influye en otras personas y en los acontecimientos. Hace cosas y las cambia y luego son distintas. Yo me quedo en esta casa, haciendo trabajos que no importan a nadie más que a mí. Yo no cambio las cosas. El trabajo que hago no cambia nada; lo que cocino desaparece, lo que limpio un día hay que volver a limpiarlo al siguiente. Me parece que estoy atrapada en algún proceso misterioso. (1970, p.243)

Las mujeres tomaban conciencia de su situación, pero también reparaban en que su permanencia en aquellas relaciones de subordinación no era una mera elección y que salir de ellas implicaba hacer frente a importantes y dolorosos retos. Expone MacKinnon:

Cuando por primera vez pensaban en serio en no casarse o en divorciarse, muchas veces descubrían su dependencia económica (...) o que les pagaban menos que a los hombres que vendían un trabajo equivalente. (...) Inextricablemente, las mujeres pueden encontrarse dependiendo también internamente: condicionadas a pensar que no son nada sin un hombre, a pensar que son menos mujeres si no lo tienen. (1995, p.168)

Al final, como sostenía Sulamith Firestone (1976, p. 9), lo característico de la concienciación feminista es que permite alcanzar una explicación sistemática de la desigualdad entre las clases sexuales, mediante la teorización del patriarcado. A pesar de las conquistas logradas desde los años setenta, todavía las mujeres (incluso en el mundo occidental) son una clase oprimida. El trabajo de las mujeres se paga menos y tiene peores condiciones. Las mujeres ocupan con mayor frecuencia los trabajos de menor interés y complejidad, de menor prestigio social, y habitualmente desarrollan trabajos de la limpieza y cuidado de las necesidades físicas que, a pesar de ser imprescindibles, tienen unas condiciones durísimas y carecen de reconocimiento. Las mujeres son la clase sexual que conforma el sujeto político del feminismo del siglo XXI y las redes sociales están permitiendo cierta recuperación de la conciencia de clase sexual que se había 
perdido en las últimas décadas, durante la tercera ola feminista (de influencia posmoderna) que se preocupó más por la diversidad entre las mujeres que por los elementos unitarios. Luisa Posada señala que las mujeres son diversas, pero que no podemos olvidar que en el mundo "la realidad material de las condiciones de vida de muchas mujeres exige todavía pensar desde el feminismo un proyecto de emancipación social" (Posada, 2014, p. 157). Necesitamos que las mujeres sean el sujeto del feminismo "Un discurso crítico con lo que todavía no es ni mucho menos calificable de postpatriarcado" (Posada, 2014, 157).

\section{CREACIÓN DE CONCEPTOS}

Miranda Fricker (2007, p. 247) señala que el poder desigual sesga el conocimiento, de modo que los poderosos disponen de las teorías que permiten interpretar sus experiencias, a las que recurren para dar sentido a lo que les pasa, mientras que es más probable que las personas indefensas tengan experiencias que son un enigma y que se vean forzadas a buscar modelos ajenos para comprenderlas, en los que dichas experiencias no acaban de encajar. La histórica subordinación de las mujeres les impidió participar en aquellas prácticas mediante las cuales se generan los significados sociales. Son prácticas de este tipo el periodismo, la política, la universidad, el derecho o la medicina. Por eso, la incorporación a estas áreas de las pioneras, no fue simple interés de "mujeres burguesas", sino que fue algo fundamental para la totalidad de las mujeres. Contar con nociones teóricas como "brecha salarial" o la necesidad de "conciliación familiar" es esencial para que una mujer que trabaja en una empresa y que no tiene suficiente tiempo para ver a su familia comprenda que sus sentimientos de frustración ante las políticas de empresa son legítimas y no indican falta de profesionalidad, ausencia de ambición o escaso compromiso con su trabajo. Fricker señala que el método de la concienciación feminista fue una respuesta directa al hecho de que buena parte de la experiencia de las mujeres era incomprensible o incluso carecía de nombre.

Eyerman y Jamison (1991) sostienen que los nuevos movimientos sociales abren un espacio idóneo para la innovación y creación de conocimiento académico. La existencia de un movimiento social plural y en continua evolución y polémica interna y externa permite que surjan nuevos y fructíferos paradigmas teóricos. Una de las virtudes de los movimientos sociales es que permiten conducir a la luz del conocimiento y la agenda política institucional lo que hasta hoy ha permanecido oculto. Las redes sociales permiten a las mujeres asociarse con otras mujeres para compartir sus experiencias de marginación o discriminación social e institucional. En este sentido las redes virtuales de feministas presentan similitudes con los grupos de conciencia que se constituyeron en los 
años setenta en los que las mujeres compartían experiencias y constataban que sus problemas personales eran producto de una estructura social.

Hoy las mujeres se reúnen en la red y mantienen debates sobre feminismo que permiten dilucidar cuestiones teóricas complejas como la diferencia entre "discriminación" y "opresión", o si existe un ideal feminista de maternidad. Movimientos como el me too, en el que las mujeres narran sus experiencias de acoso sexual, han dado lugar a hashtags que han sido trending topic en distintos países, y a la creación de grupos restringidos en los que las mujeres ponen en común sus vivencias sobre acoso en el trabajo o abuso sexual infantil.

La concienciación, en sus orígenes, no solo posibilitó la aparición de nociones como "patriarcado" o "género" sino que dio lugar a nociones innovadoras para la medicina o el derecho, entre otros campos de conocimiento. Susan Brownmiller (2000, p. 143) en su crónica autobiográfica del movimiento de liberación de las mujeres de Estados Unidos expone un ejemplo de innovación médica que se produjo en un grupo sobre salud. Wendy Sanford lidiaba con una depresión tras el nacimiento de su hijo y su amiga la llevó a una sesión feminista. Sanford describe que quedó estupefacta cuando hablaron de la depresión posparto y ella descubrió que aquello de lo que se había estado culpando a sí misma, y de lo que su esposo le culpaba, no era una deficiencia personal, sino una combinación entre cuestiones psicológicas y un asunto social real: el aislamiento. Miranda Fricker (2007, p. 240) explica que el vacío hermenéutico social sobre la experiencia de las mujeres tras el parto había generado un daño epistémico en la vida de Sanford y de muchas mujeres que pudo ser paliado gracias a la concienciación feminista.

Otro ejemplo que expone Brownmiller (2000, p. 232) es el de la creación de la categoría jurídica de "acoso sexual" mediante el método de la concienciación. Dicha noción surgió a partir del caso de Carmita Wood. Esta mujer, que era el único sustento de sus dos hijos, había trabajando ocho años en el departamento de física nuclear realizando un trabajo administrativo. Un ilustre profesor se tocaba el paquete cada vez que se acercaba a su escritorio, o se restregaba contra sus pechos al intentar alcanzar unos documentos. Un día la arrinconó en el ascensor y le dio unos cuantos besos no deseados. Tras este incidente, Wood intentó mantener a raya al profesor y conservar una relación cordial con su esposa. Esta situación le generó mucha tensión y dolor muscular crónico. Solicitó el traslado a otro departamento y, como se lo denegaron, abandonó el trabajo. Solicitó una prestación por desempleo, pero cuando el encargado de tramitar las solicitudes le preguntó porqué había dejado su trabajo Wood se mostró avergonzada al describir los episodios. Ante la insistencia (había que rellenar esa casilla del formulario), respondió que 
había sido por razones personales. La solicitud de prestación por desempleo fue denegada.

En las reuniones de concienciación feminista en las que Wood contó su historia descubrieron que todas las presentes habian tenido una experiencia parecida en algún momento y todas habían guardado silencio al respecto. Dos abogadas feministas, Susan Horn y Maurie Heins, se hicieron cargo del recurso de la prestación por desempleo de Carmita Wood y el grupo también hizo una denuncia pública para romper el silencio sobre aquello. Pero "aquello" sobre lo que iban a romper el silencio no tenía nombre. Así que ocho de ellas se reunieron en una oficina y empezaron a debatir sobre cómo definir en los carteles lo que estaban denunciando. Propusieron varios nombres intentando encontrar algo que aludiera a ese amplio conjunto de conductas persistentes, de mayor o menor sutileza. Finalmente inventaron la categoría "acoso sexual". Miranda Fricker (2007, p. 243), a partir de este relato de Brownmiller, subraya la importancia epistemológica que adquiere la concienciación. Fricker señala que en los recursos colectivos hay lagunas allí donde debería estar el nombre de determinadas experiencias sociales que afectan estructuralmente a las mujeres y esto las vuelve vulnerables ante dichos acontecimientos, impidiendo que tomen medidas frente a los mismos.

El caso de Carmita Wood conecta de forma clara con fenómenos actuales como el me too y con las movilizaciones españolas tras el caso de "la manada". Los grupos feministas continúan desempeñando esa labor de cuestionamiento de nociones sexistas, por ejemplo cuestionando la noción actual de consentimiento sexual. El feminismo denuncia que el concepto legal de consentimiento sexual se basa en la aceptación pasiva de la relación sexual por parte de la mujer y no en la búsqueda activa de placer por parte de la misma. Esta diferencia conduce a normalizar todas las relaciones sexuales que se realizan bajo chantaje emocional o incluso bajo amenaza velada, así como todas aquellas que entran en el espectro de la resignación o el débito sexual con la pareja o con el hombre que te ha pagado una copa. Las feministas cuestionan también la diferenciación jurídica entre agresión sexual y abuso sexual, que conduce al absurdo de considerar de menor gravedad la violación de una mujer ebria, drogada o con discapacidad cognitiva.

En nuestra experiencia como activistas de la endometriosis, hemos observado que cuando las mujeres afectadas por dicha enfermedad se reúnen en las redes sociales, cuestionan el tópico de que es normal que la menstruación sea dolorosa, pues una menstruación sana no debe causar más que una simple molestia. También descubren que la media de retraso para obtener un diagnóstico de esta enfermedad es de nueve años porque muchas son enviadas a salud mental o son acusadas sutilmente de ser hipocondriacas y se ven obligadas a pasar por muchos especialistas antes de ser 
tomadas en serio. Los estereotipos relativos a la debilidad de las mujeres, a la pereza y la histeria, están presentes en muchas historias. Las mujeres llegan a dudar de sus propias percepciones físicas y cuando acceden a estos grupos virtuales comprenden que todo lo que les ha ocurrido está relacionado con el androcentrismo sanitario (Cfr. Documental Mariposas Amarillas). El movimiento activista, que logra implicar a la comunidad científica, aspira a que la pregunta “¿endome-qué?" deje de ser frecuente. Allá donde existe una laguna epistémica, la ausencia de un término en el imaginario colectivo, debe situarse la palabra "endometriosis".

El testimonio de Melissa, difundido por la asociación británica endometriosis UK a través de redes sociales, es clarificador con respecto a la importancia psicológica de poner nombre a lo que te ocurre:

Con diez años ya estaba enferma. Terminé perdiendo mucho tiempo de colegio. Cuando pude regresar al colegio ya no tenía amigas, me había quedado muy atrás y seguía estando enferma (...) los otros estudiantes me miraban como si fuese distinta, porque era la única a la que se le permitía ir al baño, y eso me hacía sentir todavía más sola y aislada. Vi al doctor muchas veces (...) ¡me dijo que todo estaba en mi cabeza! Yo me sentía muy sola, nadie comprendía por lo que estaba pasando, jincluso empecé a preocuparme porque quizás todo estaba solo en mi cabeza! Con los años la enfermedad fue cada vez peor. El colegio era duro y yo tenía que poner mucho más esfuerzo que el resto solo para aguantar el día. Perdí tres trabajos, mi vida social era inexistente. Mis amistades desaparecieron y $\mathrm{mi}$ relación de pareja se vio muy afectada. (...) Sigo sin poder trabajar debido al constante dolor y a la enfermedad. (...) Ahora trabajo duro para difundir conocimientos sobre la endometriosis. Tú sabes que estás enferma y sabes que no está solo en tu cabeza. (Endometriosis UK. 2012)

Otros testimonios, difundidos a través de las redes sociales de la Asociación española Adaec, sirven también para evidenciar la importancia epistemológica del activismo en redes en el que se comparten experiencias. Uno de estos testimonios es el Judith, que expone su experiencia médica en Panamá y posteriormente el impacto sobre su vida del activismo en redes en España:

"Yo le explique al médico lo que me pasaba y el médico me dijo: "eso es mentira" (...), "tú lo que no quieres es tener relaciones con tu marido", "tú estás inventando los dolores". Creyó que yo estaba inventando los dolores. Como si pusiera una excusa típica como la del dolor de cabeza. Y no era verdad. Después de ir al médico mi ex pareja comenzó a echármelo en cara. "(...) Lo que pasa es que eres una floja, 
no quieres limpiar" (...). Me están tratando muy bien las demás muchachas de la endometriosis. (...) Siento que no estoy sola, que hay más mujeres a las que les está pasando lo mismo. (...) Ya no pienso como antes, que la sociedad no me comprende. (Aránguez, Molpeceres y Alcántara, 2019).

Otro de estos testimonios es el de Irene Atienza, que expone su experiencia en España:

Gracias a la asociación puedo aconsejar a otras mujeres para evitar que pasen por lo que yo pasé para el diagnostico y en la búsqueda de buenos profesionales, y esto hace que vuelva a sentirme útil aunque sea desde el sofá de mi casa. También me siento más fuerte al ver los testimonios de mis compañeras, y al verlas sobreponerse al sufrimiento y al dolor. Aconsejo a las mujeres que sospechen que tienen endometriosis que visiten nuestras redes. Hoy siento esperanza, porque estamos trabajando juntas para que se conozca la enfermedad. (Aránguez, Molpeceres y Alcántara, 2019)

Un tercer testimonio de las redes de Adaec es de Ivonne, que cuenta su experiencia médica, entre México y España:

(El médico) primero me dijo que estaba loca y que desperdiciaba recursos, que exageraba, pero luego además me juzgó y me puso eso en el papel y yo tuve que ir al trabajo y decir que no pude ir por aquel motivo (el médico puso en el informe de esta paciente que sangraba por mantener "prácticas sexuales poco convencionales"), ifue realmente humillante, realmente humillante! (...) Fue muy liberador saber al fin que tenía un diagnostico, que no era una exagerada. Es liberador saber que existes, que a partir de ahí te reconoces en un diagnóstico. Además a partir de ahí yo he tenido toda la autoridad para decir: "yo tengo esto, no estoy loca, no me lo invento, ¡lo tengo!”. (Aránguez, Molpeceres y Alcántara, 2019)

Además de este de la endometriosis, podrían ponerse numerosos ejemplos de grupos actuales que adquieren vitalidad por medio de internet, compartiendo experiencias sobre el parto, la lactancia o las condiciones laborales de los trabajos feminizados. La riqueza gnoseológica del feminismo se percibe en la rápida difusión a través de redes virtuales de términos que describen situaciones cotidianas antes innombradas (pensemos en palabras de alcance global como manspreading, mansplaining, sororidad y feminicidio).

\section{ESTRECHAR LAZOS ENTRE MUJERES}

Las reuniones en los grupos de conciencia de los años setenta eran una de las pocas ocasiones en la que las mujeres tenían ocasión de estar juntas sin presencia de hombres. 
MacKinnon (1995, p. 168) señala que lo más importante es que este contexto permitía valorar más a las mujeres como fuentes de información, de consejo, de estimulación, y percibir hasta qué punto se habían menospreciado las mujeres entre sí. Cuando se pararon a prestarse atención encontraron lo mucho que brillaban sus capacidades, usualmente ignoradas por la sociedad patriarcal. La proximidad entre las mujeres reveló que habían estado alejadas y que este alejamiento las privaba de la posibilidad de conceptualizar el patriarcado y de enfrentarse a su opresión.

Las mujeres del colectivo de Boston explican que reunirse entre mujeres les permitía descubrir quiénes eran, separadas de las relaciones con los hombres que habían sido hasta ese momento el centro de sus vidas. Señalan:

La mayoría habíamos tratado con mujeres cuando íbamos a la escuela, pero habíamos enfocado esas amistades como una etapa transitoria para llegar a una vida centrada en el hombre. Nos habíamos perdido algo. Antiguamente, las familias grandes proveían contactos estrechos entre mujeres que inconscientemente se daban apoyo, compartían experiencias y sabiduría. La mayoría de nosotras no vivimos en las ciudades donde vive nuestra familia. (Colectivo de Mujeres de Boston, 1979, p. 17)

Señalan que al principio temían contar sus historias, porque pensaban que serían rechazadas, malentendidas y juzgadas por las demás. Pero en lugar de eso encontraron que tenían mucho en común $\mathrm{y}$, conforme hablaban de forma más sincera, trabaron amistades genuinas.

Las mujeres de dicho colectivo explican que al reunirse se volvieron mucho más autónomas y comprendieron que ellas mismas podían hacer todas las actividades, incluida la de teorizar, y adquirieron ambición profesional, es decir, el deseo de obtener el reconocimiento por lo que hacían. Algunas mujeres del colectivo de Boston han dejado escritas sus impresiones personales. Judith cuenta:

Durante el colegio, mis mejores amigas eran mujeres. Pero después de la escuela dejé de tener una amiga principal a quien podía contarle todo. De hecho, alrededor de los catorce o quince años dejé de confesar mis sentimientos más profundos, completamente. Recuerdo que, a pesar de todas mis amigas, me sentía sola y pensaba que nadie me entendía. En ese tiempo empecé a soñar con el príncipe azul .1979, p. 63) 
Por su parte, Rachel expuso:

Al reunirnos redescubrimos un nexo común que nos permite dejar de juzgarnos a nosotras mismas y a las otras por las reglas de los hombres. Tratamos de no competir entre nosotras. Trabajamos para respetar nuestras emociones y apoyarnos mutuamente. Hemos aprendido a tomarnos en serio. (...) Cambiamos nuestras vidas, nuestras metas, nuestro medio, la definición de nuestras necesidades. (1979, p. 64)

Deborah señala:

Básicamente, la diferencia es que ya no te sientes sola. Cuando estás con alguien tienes todo el movimiento feminista detrás" (1979, p. 64). Deborah explica que ese respaldo psicológico le facilita enfrentarse al abuso de los hombres. Susanne explica: "ahora cuento realmente con otras mujeres como algo fundamental en mi vida. Ya no pienso que compartimos el tiempo porque no estamos casadas o no estamos con hombres. (1979, p. 65)

La concienciación también permitía encontrar similitudes entre las experiencias de las mujeres de distintas clases sociales, y esto les conducía a concluir que la clase sexual era una categoría autónoma con respecto a la clase social. Las feministas de Wetschester exponen este testimonio de una mujer acomodada:

Vivimos con comodidad solo en la medida en que nuestros hogares, nuestra ropa y los servicios que recibimos alimentan y sustentan la categoría y el ego de los hombres que nos mantienen. (...) Como seres humanos, como individuos, en realidad tenemos muy poco, y si nuestros maridos nos abandonaran o si nosotras los abandonáramos, nos encontraríamos con el cuidado y la responsabilidad de los hijos sin dinero, sin trabajo, sin crédito y sin poder. Por esta condición incuestionable hemos pagado el precio del aislamiento y la explotación a través de las instituciones del matrimonio, la maternidad, la psiquiatría y el consumismo. Aunque nuestra forma de vida puede parecer mejor desde el punto de vista material, estamos, como todas las mujeres, dominadas por los hombres en la casa, en la cama y en el trabajo, emocional, sexual, doméstica y económicamente. (Westchester Radical Feminists, 1972, p. 385)

En la época de las redes sociales, estas narraciones de los años setenta nos resultan muy familiares. Nuestras experiencias vitales de vulnerabilidad y sufrimiento siguen constituyendo el punto de partida de una reflexión colectiva que se produce en internet y 
que a veces adopta la apariencia de un simple desahogo. Pero hoy, igual que ayer, la comprensión del carácter estructural de nuestros problemas privados nos ayuda a reinterpretar la propia vida, deshacernos de culpas y revalorizar la palabra de las mujeres. Aquellas vivencias de subordinación que no nos atrevemos a contar por temor a que sean convertidas por el patriarcado en causas de estigma, constituyen en el interior de las redes de mujeres un vínculo común de hermandad. Los sentimientos solitarios de vulnerabilidad e impotencia, cuando nos unimos se transforman en una apasionada indignación y en un férreo afán de transformación con un poderoso alcance viral. La unión virtual entre mujeres en torno a causas o principios comunes puede cobrar una importancia enorme para superar los problemas del día a día. Por ejemplo, una joven estadounidense afroamericana con endometriosis que expresa sentirse incomprendida por el sistema médico y laboral comienza sus post de redes sociales rezando por todas sus "endosisters" (endohermanas) del mundo. Esta misma joven recabó direcciones postales de "endosisters" de todo el mundo y les hizo llegar postales dibujadas por ella con una dedicatoria personalizada.

Es muy habitual en los círculos feministas virtuales que las mujeres expongan vivencias personales vinculadas al sexismo y la incomprensión y que reciban apoyo de otras mujeres que exponen en ese hilo la similitud con sus propias historias. Esto conduce a las mujeres feministas a tener la sensación de estar respaldadas y acompañadas en alguna medida, incluso cuando el entorno cercano es hostil o en aquellos casos en los que la mujer vive muy aislada. Las mujeres somos la mitad de la población y el patriarcado atraviesa el mundo entero. Por ello los grupos de conciencia (articulados en torno a experiencias de opresión comunes) pueden alcanzar una dimensión global y la comunidad de hermanas tiene una creciente capacidad para promover movilizaciones basadas en reivindicaciones similares en puntos alejados del planeta.

\section{5. ¿PUEDE OBTENERSE CONOCIMIENTO OBJETIVO PARTIENDO DE LAS EXPERIENCIAS DE LAS MUJERES?}

MacKinnon señala que "la posición de poder de los hombres sobre las mujeres es una parte básica de lo que define a los hombres como hombres ante sí mismos, y a las mujeres como mujeres ante sí mismas" (1995, p.168). La autora señala que "examinando minuciosamente la vida de las mujeres caso por caso, detalle por detalle, no es extraño que las mujeres sean quienes son tal y como han sido tratadas" (1995, p. 165). El cuidado, la intuición, la fragilidad, la orientación hacia los niños, el talento para el cuidado del hogar y la decoración parecen simplemente descripciones de las características exigidas a las personas que desempeñan un rol. No son rasgos que se tengan por 
herencia, ni por accidente, sino rasgos que se adquieren por deformación, pues se obliga a las mujeres a realizar los trabajos de servicio y a ser incapaces de hacer cualquier cosa que exija fuerza, como abrir botellas. Cuando se descubre el peso de la socialización, los fallos individuales dejan de parecer individuales. "Las mujeres se enfadan cuando ven que sus vidas son una sucesión de avenidas bloqueadas por el sexo", sostiene MacKinnon (1995, p.166).

En el sistema patriarcal la ideología de la masculinidad/feminidad opera moldeando la identidad. Por supuesto, como tristemente sabemos, los hombres también utilizan la violencia física y la intimidación para mantener el control sobre la clase sexual de las mujeres. Pero normalmente no es necesario el ejercicio de la violencia expresa, ya que suele bastar con la invalidación de la identidad: eres mala, una puta, un fracaso como mujer. Aunque las mujeres asuman racionalmente que las tareas tradicionales no son su exclusiva responsabilidad, todavía son ellas las que se sienten culpables de que la casa esté desordenada o de que el trabajo les impida estar suficientemente pendientes de las niñas. Las mujeres aprenden a responder a estos mandatos sociales porque existen indulgencias y privaciones materiales que los respaldan. MacKinnon señala al respecto:

Comprender que un grupo social reconocido posee y utiliza estas armas sobre otros en beneficio propio es algo poderoso. (...) Las mujeres ven que los hombres logran muchas ventajas de los papeles de las mujeres, incluidos el ser servidos y tenidos en cuenta, ser apoyados y mantenidos, tener bien atendidos a sus hijos y cubiertas sus necesidades sexuales, y liberarse de la necesidad de hacer tareas secundarias que consideran demasiado bajas para ellos a menos que no haya otro trabajo (o una mujer) a mano. (1995, p. 182)

El dominio masculino está presente incluso en la cabeza de las mujeres, porque a causa de los mandatos sociales es muy fuerte la necesidad de evitar el castigo. El castigo puede ser el rechazo a una misma, la sensación de fracaso. No es irracional que, en este contexto, las mujeres sientan que su papel es tolerable y hasta satisfactorio. La ideología de la feminidad intenta revestir de satisfacción esos servicios que proporcionan las mujeres (pero si fuesen tan satisfactorios, los hombres los realizarían). La repetición cotidiana genera la apariencia de que las cosas se hacen por deseo e incluso por una propensión innata. Las mujeres llegan a considerar sus rasgos físicos sexualmente atractivos como seña de identidad, de modo que se valoran en relación con unos parámetros culturales que giran en torno a la apetencia sexual de los hombres. El condicionamiento femenino consiste en que las mujeres se perciban a sí mismas con ojos de hombre y así garantizar su aceptación sin preguntas de una existencia definida por 
ellos. En cambio, el objetivo del condicionamiento de los hombres es que se perciban a sí mismos y sus vidas con sus propios ojos, y así prepararlos para una existencia en sus propios términos.

Las mujeres están socialmente definidas de un modo tal que ni siquiera pueden vivirse, sentirse o percibirse como algo distinto de su definición impuesta. Por eso podríamos cuestionarnos si existe tal cosa como la auténtica experiencia de las mujeres más allá de la deformación patriarcal. La concienciación es el método que planta cara a esta paradoja epistémica. MacKinnon explica:

Darse cuenta de que las mujeres se reconocen en buena medida en estereotipos sexuales, de que de verdad sienten las necesidades que se les ha animado a sentir, de que de verdad se sienten realizadas de la forma esperada, de que a menudo eligen ciertamente lo que se ha prescrito, hace posible la comprensión de que las mujeres, al mismo tiempo, no se reconocen en ese lugar, no lo sienten, ni lo han elegido. (1995, p. 182)

Las mujeres del Colectivo de Boston exponen que, al hablar sobre lo que la vida había supuesto para ellas por ser mujeres, alcanzaban una nueva visión de sí mismas, una perspectiva nueva de lo que significa ser mujer. Señalan que cuando evaluaban sus situaciones presentes constataban que aún pensaban en términos sexistas, que otorgaban más valor a lo que decían y hacían los hombres que a lo que decían o hacían otras mujeres. Es decir, vivían como si hubiera algo intrínsecamente inferior en ellas. Gracias a las reuniones experimentaban orgullo de ser mujeres. Además, la unión entre mujeres permitía debilitar esa fantasía que vertebraba sus vidas, el deseo de encontrar un hombre que diera sentido a sus existencias, que las hiciera sentir vivas (1976, p.20).

Hay una aparente contradicción entre el hecho de que el feminismo aspire a representar la auténtica experiencia de las mujeres y simultáneamente admita que el punto de vista de las mujeres está moldeado por la misoginia social. La importancia de resolver esta paradoja epistémica es crucial, porque como explica MacKinnon: "La lucha por la conciencia es la lucha por el mundo: por una sexualidad, una historia, una cultura, una comunidad, una forma de poder, una experiencia de lo sagrado" (1995, p. 185). La concienciación comienza en el momento en el que las mujeres comparten con otras la intuición de que esa vida de las mujeres no es la única posible, no es suficiente, no es realmente suya y no es justa. Algunas mujeres, desde la aceptación de ciertos roles patriarcales, acusan al feminismo de arrogarse la voz de las mujeres y sostienen que no existe esa voz. Así, algunas acusan a las feministas de puritanas en términos sexuales o 
de intentar apropiarse de la noción misma de feminismo. Pero no podemos aceptar como feminista cualquier experiencia de una mujer. No puede aceptarse esta posición subjetivista porque parte de la premisa de que las mujeres son libres, tienen un espacio considerable para elegir, o de que los problemas se resuelven reinterpretando lo que les ocurre. Cuando algunas mujeres niegan la desigualdad entre los sexos o sostienen que las mujeres tienen poder para hacer lo que quieren, están faltando a la realidad más elemental que muchas mujeres viven en su carne.

Aunque el feminismo surge de la experiencia de las mujeres no es subjetivo ni una visión parcial entre otras posibles. El patriarcado existe como realidad material que se impone sobre todas las dimensiones de nuestras vidas de forma absolutamente real. El feminismo reclama que la experiencia colectiva de las mujeres es el mejor camino para acceder a la comprensión de ese sistema de opresión. El conocimiento se obtiene a partir del análisis de las condiciones concretas de todas las mujeres como sexo, rompiendo con la concepción individualista de la epistemología liberal que ha definido el método científico. El feminismo cuestiona la universalidad liberal, pero no por ello se reduce a subjetividad.

\section{CONCLUSIONES}

Concluimos que, a pesar de las décadas transcurridas y las innovaciones tecnológicas, la cuarta ola feminista comparte con la segunda ola su elemento central: el método de la concienciación. El intercambio en red continua permitiendo que surja la conclusión "de que lo personal es político" y los nuevos grupos "difusos" de concienciación de la era digital reproducen de forma natural los elementos clásicos del método de la toma de conciencia. El resultado continúa siendo la conciencia de "clase sexual" (las mujeres como sujeto político) que constituye el germen de la acción colectiva.

De los grupos de concienciación de los setenta emergieron conceptos fundamentales del feminismo como el de patriarcado o el de clase sexual. Si el feminismo de los años setenta fue revolucionario, el feminismo de nuestros días tiene un potencial muy superior. Las redes sociales conectan diariamente a las mujeres y permiten una comunicación a escala global. Los saberes de las autoras feministas, ausentes en los planes de estudios, se transmiten a través de blogs y post de Facebook, en una auténtica Academia virtual en la que se producen interesantes disquisiciones filosóficas. Todo este intercambio virtual no solo se refleja en grandes movilizaciones e influye sobre la agenda política, sino que además permea la totalidad de la estructura social modificando la vida cotidiana. Es decir, una virtud del feminismo es su capacidad para modificar la cultura presente en la vida diaria y esta es una de las características inherentes a su énfasis en la conciencia. Aunque para otras luchas colectivas también es importante la conciencia (por ejemplo, la 
conciencia de clase para el marxismo), para el feminismo la fase de toma de conciencia colectiva cobra una importancia superior porque el patriarcado está especialmente arraigado en la identidad de las mujeres. Tal vez por eso el feminismo no puede conceder a la ideología un lugar secundario con respecto a lo material y esto distingue a la lucha de las mujeres del marxismo ortodoxo. Como sostiene Sheila Rowbotham, "un grupo oprimido debe hacer añicos en seguida el mundo reflejado en sí mismo que lo rodea y, al mismo tiempo, proyectar su propia imagen en la historia. Para descubrir su propia identidad como algo distinto de la del opresor, tiene que ser visible para sí mismo. Todos los movimientos revolucionarios crean su propia forma de ver" (1973, p. 136).

Kate Millett (2010, p. 609) enfatiza la importancia que tiene en el feminismo la transformación de la conciencia y considera que este cambio cultural es incluso más importante que la transformación de las estructuras económicas. La autora se muestra esperanzada al observar el alcance global del feminismo y considera que las mujeres representan una de las fuerzas más cruciales para la transformación social, por ser el grupo alienado más numeroso, y en virtud de su ira contenida. El sexo femenino, considera, podría desempeñar, en la transformación social, una función de liderazgo, inspirando a la movilización de los diversos grupos oprimidos como las clases desposeídas y las personas racializadas. La filósofa se muestra escéptica con las revoluciones armadas, idolatradas por la tradición revolucionaria masculina y señala, como una de las señas de identidad del feminismo, la confianza en el poder de la educación y la conciencia como motor del cambio.

Millett considera que esto no conducirá necesariamente a una lenta y penosa evolución y añade (anticipándose a lo que estamos experimentando en la cuarta ola del movimiento feminista en el siglo XXI) que hemos de tener en cuenta "la aceleración deliberada de los procesos sociales que puede conseguirse gracias a las técnicas modernas de comunicación, en una época en la que resulta factible organizarse internacionalmente en un espacio de tiempo inferior". Hoy vemos que con las redes sociales resulta más sencillo influir sobre la cultura y acceder a experiencias de mujeres que viven circunstancias similares. Esto hace posible el cuestionamiento la subordinación aprendida. Según Melucci (1994, p. 58), los nuevos movimientos sociales constituyen unos auténticos laboratorios culturales en los que se cuestiona lo que se tenía por real. Los debates constantes en las redes, con sus tendencias y tensiones, permiten delimitar los problemas y plantear estrategias de acción transformadora. 


\section{Referencias}

Aránguez, T., Molpeceres, M., Alcántara, P. (2019). Se acabó el silencio. Feminismo: Salud, Cuidados, Autonomía. Cáceres: La Moderna.

Brownmiller, S. (2000). In Our Time: Memoir of a Revolution. London: Aurum Press Ltd.

Colectiva Mujeres de Boston (1976). Nuestros cuerpos, nuestras vidas. Cali: Colectivo de Mujeres de Cali.

De miguel, A. (2015). Neoliberalismo sexual. El mito de la libre elección. Madrid: Cátedra.

Eyerman, R. y Jamison, A. (1991). Social Movements. A Cognitive Approach. Pensilvania. The Pensilvania State University Press.

Firestone, S. (1979). La dialéctica del sexo. El defensa de la revolución feminista. Barcelona: Kairós.

Freeman, J. (1988). La Tiranía de la Falta de Estructuras. Madrid: Forum de política feminista.

Fricker, M. (2007). Injusticia epistémica. Barcelona: Herder.

Endometriosis UK (2012). Focus: is it normal? Endolink Magazine (1-10).

Gadamer, H. (2013). Verdad y método. Salamanca: Sígueme.

Posada, L. (2014) Teoría queer en el contexto español. Reflexiones desde el feminismo. Daimon. Revista Internacional de Filosofía. 63, 147-158.

MacKinnon, C. (1995). Hacia una teoría feminista del Estado. Madrid: Cátedra.

Mccarthy, J. y Zald, M. (1977). Resource mobilization and social movements: A Partial Theory. American Journal of Sociology. 82, 1212-1241.

Melucci, A. (1994). ¿Qué hay de nuevo en los nuevos movimientos sociales? En E. Laraña y J. Gusfield (Eds.), Los nuevos movimientos sociales. Madrid: CIS.

Millett, K. (2010). Política sexual. Madrid: Cátedra.

Rowbotham, S. (1973). Women's Consciousness, Man's World. Baltimore: Penguin.

Tax, M. (1970). Woman and Her Mind, The Story of Daily Life. Boston: Bread and Roses.

Westchester Radical Feminists. (1972). Statement of Purpose, May, 1972. Koedt, Levine y Rapone, Radical Feminism. 385-386. 